\title{
Thermodynamic study on the reactivity of trace organic contaminant with the hydroxyl radicals in waters by advanced oxidation processes
}

\author{
Yuanhui Ji ${ }^{\mathrm{a}}$, Zhuhong Yang ${ }^{\mathrm{a}}$, Xiaoyan Ji ${ }^{\mathrm{b}}$, Wenjuan Huang ${ }^{\mathrm{a}}$, Xin Feng ${ }^{\mathrm{a}}$, Chang Liu ${ }^{\mathrm{a}}$, \\ Linghong $\mathrm{Lu}^{\mathrm{a}}$, Xiaohua $\mathrm{Lu}^{\mathrm{a}, *}$ \\ a State Key Laboratory of Materials-Oriented Chemical Engineering, Nanjing University of Technology, Nanjing 210009, Jiangsu, China \\ ${ }^{\mathrm{b}}$ Division of Energy Engineering, Luleå University of Technology, SE-97187 Luleå, Sweden
}

\section{A R T I C L E I N F O}

\section{Article history:}

Received 2 August 2008

Received in revised form 29 October 2008

Accepted 31 October 2008

Available online 8 November 2008

\section{Keywords:}

Advanced oxidation process

Thermodynamic data

$\mathrm{TiO}_{2}$ photocatalysis

Degradation

Trace aqueous organic contaminants

\begin{abstract}
A B S T R A C T
This paper is to investigate the degradation abilities of various chlorinated aliphatics, benzene and its derivatives in order to treat organic polluted wastewaters efficiently by advanced oxidation processes (AOPs). A thermodynamic method is proposed to calculate the standard molar Gibbs energy of formation for aqueous organic species. Using the method proposed, the standard molar Gibbs energies of formation for 31 aqueous organic species are obtained. Moreover, the molar Gibbs energy change of reaction $\Delta_{r} G_{m}^{0}$ for the organic species with hydroxyl radicals is calculated from the standard molar Gibbs energy of formation for aqueous organic species to determine the degradation order of ease for the organic species. New photocatalytic experiments are carried out for the model verification. The calculation results of the model agree with the available and new experimental results. This work shows that the thermodynamics of the degradation reaction for the organic pollutants in AOPs can find the corresponding relationships with the degradation reaction rate by experimental measurements. The work in this paper represents a success of thermodynamics for the application in environmental area.
\end{abstract}

(c) 2008 Elsevier B.V. All rights reserved.

\section{Introduction}

The widespread pollution of surface, ground, and drinking water or effluents with toxic and hazardous organic pollutants demands great efforts toward the technology development for the treatment of such waters. The removal of the contaminants has traditionally been accomplished using biological treatments, incineration, adsorption over activated carbon or gas-phase stripping [1,2]. The advanced oxidation processes (AOPs) are the alternative and widely used processes for the treatment of drinking water sources and for the remediation of contaminated groundwater. AOPs include highfrequency ultrasound waves, $\gamma$ rays or high-energy electrons, $\mathrm{TiO}_{2}$ and ultraviolet (UV) radiation, $\mathrm{H}_{2} \mathrm{O}_{2}$ and $\mathrm{UV}$, ozone $\left(\mathrm{O}_{3}\right)$ and $\mathrm{UV}$, $\mathrm{O}_{3}$ with $\mathrm{H}_{2} \mathrm{O}_{2}$, the Fenton reaction $\left(\mathrm{H}_{2} \mathrm{O}_{2} / \mathrm{Fe}^{2+}\right)$, and various combinations of these processes [3-6], which are generally expected to result in the complete mineralization of all hazardous compounds. They have attracted a growing scientific and technological interest over the last 20 years, and their applicability for the oxidation of several model pollutants has been experimentally verified $[3,5,7,8]$.

\footnotetext{
* Corresponding author at: College of Chemistry and Chemical Engineering, Nanjing University of Technology, Nanjing 210009, Jiangsu, China. Tel.: +862583588063; fax: +862583588063.

E-mail address: xhlu@njut.edu.cn (X. Lu).
}

AOPs are characterized by the generation of hydroxyl radicals $(\bullet \mathrm{OH})$, neutral species of high oxidizing power, to react rapidly on many organic compounds present in water in an unselective way [9]. It is very important to determine the reactivity order for the better design of integration AOPs. Recently, many kinetic measurements for AOPs have been performed to obtain the degradation rate constants [8] which indicate the degradation order of ease for organic compounds [7], i.e. the larger the rate constant, the faster and easier the organic compound is degraded. However, for some organic compounds, the degradation order obtained in different research groups is inconsistent. For example, for chlorinated methane, Ollis [7] investigated the mineralizations by $\mathrm{TiO}_{2}$ photocatalysis and found that the relative reactivities were $\mathrm{CHCl}_{3}>\mathrm{CH}_{2} \mathrm{Cl}_{2} \gg \mathrm{CCl}_{4}$, and the same results were obtained by the investigations for the efficiency of the $\mathrm{H}_{2} \mathrm{O}_{2} / \mathrm{UV}$ process in reference [10], while in the work of Sabin et al. [8] by $\mathrm{TiO}_{2}$ photocatalysis, the order was $\mathrm{CH}_{2} \mathrm{Cl}_{2}>\mathrm{CHCl}_{3} \gg \mathrm{CCl}_{4}$, and according to the photocatalytic degradation over irradiated $\mathrm{TiO}_{2}$ investigated at $\mathrm{pH} 5$ and $\mathrm{pH} 11$ under anaerobic conditions by Calza et al. [11], dechlorination of chloromethanes was achieved with degradation rates in the order $\mathrm{CCl}_{4}>\mathrm{CHCl}_{3}>\mathrm{CH}_{2} \mathrm{Cl}_{2}$. As for benzene and its derivatives, from the investigations for the efficiency of the $\mathrm{H}_{2} \mathrm{O}_{2} / \mathrm{UV}$ process in reference [10] determined in a flow reactor, the degradation order was toluene $>$ benzene $>$ phenol $>$ chlorobenzene, while Glaze and Kang [12] summarized the rate constants of several 
organic compounds with $\bullet \mathrm{OH}$ radicals according to the work of Farhataziz and Ross [13] and revealed that the degradation rate order was benzene $>$ toluene $>$ chlorobenzene, which represented the different reactivity order of benzene and toluene. Besides, in the work of Sabin et al. [8] by $\mathrm{TiO}_{2}$ photocatalysis, the first-order rate constants for the catalytic photo-oxidation of organic substrates under standard conditions were obtained, which were in the order: 1,2-dichlorobenzene > benzene > chlorobenzene. It is obvious that the mineralization abilities from the decomposition rate constants of some organic compounds reported in the literatures are not compatible with each other in the order. The differences of the degradation order may attribute to the different experimental conditions, data analysis using different rate equations and the experimental errors. As ${ }^{\bullet} \mathrm{OH}$ is the main oxidant generated in AOPs, the aim of this paper is to find an effective thermodynamic method to determine the degradation reaction ability for the organic pollutants by studying the mineralization reaction for the organic species with the oxidant $\bullet \mathrm{OH}$, which may find the essence of the degradation reaction ability for the organic pollutants by AOPs.

It is well known that the negative value of the Gibbs free energy change of reaction $\left(\Delta_{r} G^{0}\right)$ indicates the thermodynamic possibility of a reaction or process to occur, and the magnitude of $\Delta_{r} G^{0}$ for a reaction tells us how far the standard state is from equilibrium, which shows that the magnitude of $\Delta_{r} G^{0}$ may indicate the driving force for the chemical reactions. Besides, could the value of $\Delta_{r} G^{0}$ for the reaction of organic contaminants with ${ }^{\bullet} \mathrm{OH}$ in AOPs represent the mineralization degree of ease accurately and give an insight into reactivity order? Since no research on the mineralization reaction of organic pollutants with $\bullet \mathrm{OH}$ in AOPs by applying thermodynamics have been reported, the goal of this work is to investigate the reactive abilities of various organic species with ${ }^{\bullet} \mathrm{OH}$ in various AOPs by calculating $\Delta_{r} G^{0}$ for the mineralization reaction. A simple thermodynamic method will be used to calculate the standard molar Gibbs energy of formation for aqueous organic species, and then the molar Gibbs energy change of reaction $\Delta_{r} G_{m}^{0}$ for the organic species with hydroxyl radicals will be calculated to determine the degradation order. The calculation results will be verified by comparing with the available and new experimental results carried out in this work.

\section{Experimental materials and methods}

\subsection{Reagents, chemicals, analytical equipment and methods}

Benzene, toluene, 1,2-xylene, dichloromethane, trichloromethane, Shanghai Lingfeng Chemical Reagent Co. Ltd., AR; chlorobenzene, Shanghai Lingfeng Chemical Reagent Co. Ltd., CP; tetrachloromethane, Shanghai Rongrun Chemical Reagent Co. Ltd., AR.

The titanium dioxide $\left(\mathrm{TiO}_{2}\right)$ photocatalyst is Degussa P-25 (from Germany) with the specific surface area of $50 \mathrm{~m}^{2} \mathrm{~g}^{-1}$, the mass ratio of the anatase and rutile is about 4. XPA-II Model Photochemical Reactor (Nanjing Xujiang Company); SP-6890 Model gas chromatograph (Lunan Ruihong Chemical Instrument Company); quartz capillary chromatographic column: fixed phase SE-54, boiling room $210^{\circ} \mathrm{C}$, initial temperature $150{ }^{\circ} \mathrm{C}$, measuring room $210^{\circ} \mathrm{C}, 0.32 \mathrm{~mm} \times 30 \mathrm{~m}$; filling column: $10 \%$ DEGA, 401 organic support (180-250 $\mu \mathrm{m}), 3 \mathrm{~mm} \times 2 \mathrm{~m}$; UV-vis spectrometer (PerkinElmer Instruments, Lambda 35 Model); SCHOTT-GERÄTE pH-meter (Model CG0841, Germany).

\subsection{Photocatalytic degradation reaction}

XPA-II Model Photochemical Reactor is used for the photocatalytic degradation reaction of the organic pollutants with an immersed medium-pressure $\mathrm{Hg}$ lamp of $300 \mathrm{~W}$. The volume of the reactor is 1.01 . The reactant solutions are stirred by a magnetic stirrer in order to keep the catalyst suspending in the solutions.

P25 and $\mathrm{H}_{2} \mathrm{O}$ are dispersed by ultrasonic concussion for $10 \mathrm{~min}$ and they are put into the reactor with organic solutions. Then the magnetic stirrer and ultraviolet lamp are turned on, air flow into the reactor with the flow rate of $200 \mathrm{ml} \mathrm{min}^{-1}$. After the sample for analysis is taken out, the catalyst is removed by filtration using filtration membrane with $0.22 \mu \mathrm{m}$.

\subsection{Analytical equipment and methods}

The concentrations of benzene, toluene, 1,2-xylene, chlorobenzene are detected by capillary chromatographic column; the concentrations of dichloromethane, trichloromethane, tetrachloromethane are determined by measurement of $\mathrm{Cl}^{-}$concentrations for the product with ion selective electrodes; the concentrations of phenol are measured by ultraviolet spectrophotometry.

\section{Thermodynamic model}

Generally, the toxic organics to be treated in the surface water for the drinking water production are dissolved in aqueous solutions with very low concentrations but high toxicity. The standard thermodynamic properties for aqueous organic species are required to investigate the Gibbs free energy change for the degradation reaction in AOPs, the reliable data are unavailable for most of aqueous toxic organic species. In this paper, a thermodynamic method is proposed to calculate the standard molar Gibbs energy of formation for aqueous organic species.

\subsection{Thermodynamic modeling}

For the thermodynamic process (I)-a gaseous organic compound $A$ dissolves into water

$A\left(p_{A}, \mathrm{~g}\right) \rightarrow A\left(x_{A}, \mathrm{aq}\right)$

the change of partial molar Gibbs energy can be written as

$\Delta_{\mathrm{g}}^{\mathrm{aq}} G_{m}=\mu_{A}(\mathrm{aq})-\mu_{A}(\mathrm{~g})$

where $\Delta_{\mathrm{g}}^{\mathrm{aq}} G_{m}$ is the change of partial molar Gibbs energy for the above process (I), $\mu_{A}$ is the chemical potential of $A$ in a gaseous or aqueous phase.

The gaseous organic compound $A$ can be considered as an ideal gas because of the low pressure, and

$\mu_{A}(\mathrm{~g})=\mu_{A}^{0}(\mathrm{~g})+R T \ln \frac{p_{A}}{p^{0}}$

where $\mu_{A}^{0}(\mathrm{~g})$ is the standard chemical potential of $A$ in the gaseous phase; $p_{A}$ is the partial pressure of $A$ in the gaseous phase; and $p^{0}$ is the standard pressure. Generally, the standard pressure is defined as: $p^{0}=1.01325 \times 10^{5} \mathrm{~Pa}$.

Since the solubility of $A$ in water is very low, it is reasonable to assume the formed aqueous solutions to be an ideal dilute solution, and

$\mu_{A}(\mathrm{aq})=\mu_{A}^{0}(\mathrm{aq})+R T \ln \frac{x_{A}}{x^{0}}$

where $\mu_{A}^{0}(\mathrm{aq})$ is the standard chemical potential of $A$ in the aqueous solution; $x_{A}$ is the molar fraction of $A$ in the aqueous solution; and $x^{0}$ is the standard molar fraction in the aqueous solution. Generally, the standard molality of the solute $m^{0}$ is defined to be $1 \mathrm{~mol} \mathrm{~kg}^{-1}$, and $x^{0}$ is obtained by 
Table 1

The calculated standard molar Gibbs energy of formation at $298.15 \mathrm{~K}$ for four aqueous organic species $\Delta_{f} G_{m, A}^{0}($ aq, cal).

\begin{tabular}{|c|c|c|c|c|}
\hline System & Calculated $\Delta_{f} G_{m, A}^{0}(\mathrm{aq}, \mathrm{cal})\left(\mathrm{kJ} \mathrm{mol}{ }^{-1}\right)$ & Experimental [16] $\Delta_{f} G_{m, A}^{0}(\mathrm{aq}, \exp )\left(\mathrm{kJ} \mathrm{mol}^{-1}\right)$ & $\frac{\Delta_{f} G_{m, A}^{0}(\mathrm{aq}, \exp )-\Delta_{f} G_{m, A}^{0}(\mathrm{aq}, \mathrm{cal})}{\Delta_{f} G_{m, A}^{0}(\mathrm{aq}, \exp )}$ & (\%) \\
\hline Benzene & 133.9395 & 133.8880 & 0.0385 & \\
\hline Toluene & 126.6915 & 126.6926 & 0.0009 & \\
\hline Ethylbenzene & 136.2446 & 135.8198 & 0.3128 & \\
\hline Formaldehyde & -126.1777 & -129.7040 & 2.7187 & \\
\hline
\end{tabular}

$$
\begin{aligned}
x^{0}= & \frac{1 \mathrm{~mol}}{(1000 \mathrm{~g} /(18 \mathrm{~g} / \mathrm{mol}))+1 \mathrm{~mol}} \times 100 \% \approx \frac{1 \mathrm{~mol}}{1000 \mathrm{~g} /(18 \mathrm{~g} / \mathrm{mol})} \\
& \times 100 \%=0.018
\end{aligned}
$$

Eqs. (2) and (3) are substituted into Eq. (1), and Eq. (4) is obtained.

$\Delta_{\mathrm{g}}^{\mathrm{aq}} G_{m}=\left(\mu_{A}^{0}(\mathrm{aq})-\mu_{A}^{0}(\mathrm{~g})\right)+R T \ln \frac{x_{A} / x^{0}}{p_{A} / p^{0}}$

Let $\mu_{A}^{0}(\mathrm{aq})-\mu_{A}^{0}(\mathrm{~g})=\Delta_{\mathrm{g}}^{\mathrm{aq}} G_{m}^{0}$ and $\left(x_{A} / x^{0}\right) /\left(p_{A} / p^{0}\right)=K^{\theta}$, then

$\Delta_{\mathrm{g}}^{\mathrm{aq}} G_{m}=\Delta_{\mathrm{g}}^{\mathrm{aq}} G_{m}^{0}+R T \ln K^{\theta}$

where $\Delta_{\mathrm{g}}^{\mathrm{aq}} G_{m}^{0}$ is the change of standard partial molar Gibbs energy for the above process (I)

At equilibrium $\Delta_{\mathrm{g}}^{\mathrm{aq}} G_{m}=0$. From Eq. (5) we have

$\Delta_{\mathrm{g}}^{\mathrm{aq}} G_{m}^{0}=-R T \ln K^{\theta}=-R T \ln \frac{x_{A} / x^{0}}{p_{A} / p^{0}}$

The system here follows the Henry's law [14,15] at the pressure of $P$ and the temperature of $T$. That is,

$p_{A}=k_{A, w}^{p x} \cdot x_{A}$

where $k_{A, w}^{p x}$ is the Henry's law constant for organic species $A$ in aqueous solution.

From Eq. (6), we have:

$\Delta_{\mathrm{g}}^{\mathrm{aq}} G_{m}^{0}=-R T \ln \left(\frac{1}{k_{A, w}^{p x}}\right)+R T \ln \frac{x^{0}}{p^{0}}$

For the process (I),

$\Delta_{\mathrm{g}}^{\mathrm{aq}} G_{m}^{0}=\Delta_{f} G_{m, A}^{0}(\mathrm{aq})-\Delta_{f} G_{m, A}^{0}(\mathrm{~g})$

where $\Delta_{f} G_{m, A}^{0}$ is the standard molar Gibbs energy of formation for organic species $A$ in a gaseous or aqueous phase and the standard molar Gibbs energy of formation for aqueous organic species $A$ can be obtained by Eq. (10).

$\Delta_{f} G_{m, A}^{0}(\mathrm{aq})=\Delta_{f} G_{m, A}^{0}(\mathrm{~g})+R T \ln \frac{x^{0}}{p^{0}}-R T \ln \left(\frac{1}{k_{A, w}^{p x}}\right)$

\subsection{Model verification}

The standard molar Gibbs energies of formation for four aqueous organic species have been determined experimentally in reference [16]. The thermodynamic method described above was used to calculate the standard molar Gibbs energies of formation for these four aqueous organic species in order to verify the reliability and accuracy of the method proposed. Both the experimental and calculated results with the absolute average deviation are listed in Table 1 . As shown in Table 1, the maximum deviation is less than $3 \%$, which implies that the thermodynamic properties calculated in this paper are reliable.

\section{Results and discussions}

\subsection{Thermodynamic calculation}

\subsubsection{Calculation of standard molar Gibbs energy of formation for aqueous organic species}

Using the thermodynamic method proposed, $\Delta_{f} G_{m, A}^{0}(\mathrm{aq})$ for the 31 common-used organic species in AOPs are calculated from Eq. (10) in which the standard molar Gibbs energies of formation for gaseous $A$ and their corresponding Henry's law constants are taken from literatures. Table 2 summarized the data used and the calculated results.

4.1.2. Calculation of the molar Gibbs energy change of reaction $\Delta_{r} G_{m}^{0}$ for the organic species with $\bullet \mathrm{OH}$

From the standard molar Gibbs energy of formation for aqueous organic species, the molar Gibbs energy change of reaction $\Delta_{r} G_{m}^{0}$ can be calculated for AOPs. In this paper, $\Delta_{r} G_{m}^{0}$ for 8 organic species with ${ }^{\bullet} \mathrm{OH}$ have been investigated. To make the $\Delta_{r} G_{m}^{0}$ comparable, all the reactions are studied with the carbon dioxide produced as $1 \mathrm{~mol}$.

The mineralization reaction equations for halogenated hydrocarbon are described as in references [7,8] with $\mathrm{O}_{2}$ as the initial oxidant reactant. However, actually the produced $\bullet \mathrm{OH}$ was the effective and contributing oxidant because of its high oxidizing power. So here, ${ }^{\bullet} \mathrm{OH}$ is used as the oxidant instead of $\mathrm{O}_{2}$ in the mineralization reaction equations. In order to describe the calculation process, benzene is selected as an example. In the calculation of $\Delta_{r} G_{m}^{0}$, the standard molar Gibbs energy of formation for ${ }^{\bullet} \mathrm{OH}$, $\mathrm{CO}_{2}$ and halogen ions in aqueous solutions are required. The requisite thermodynamic data are obtained from literatures and listed in Table 3.

The reaction equation of benzene with ${ }^{\bullet} \mathrm{OH}$ can be written as

$\frac{1}{6} \mathrm{C}_{6} \mathrm{H}_{6}(\mathrm{aq})+5 \bullet \mathrm{OH}(\mathrm{aq}) \rightleftharpoons 3 \mathrm{H}_{2} \mathrm{O}(\mathrm{l})+\mathrm{CO}_{2}(\mathrm{aq})$

For Reaction (II), the molar Gibbs energy change of reaction can be calculated as

$$
\begin{aligned}
\Delta_{r} G_{m}^{0}= & \sum_{B} v_{B} \Delta_{f} G_{m}^{0}(B)=3 \Delta_{f} G_{m}^{0}\left(\mathrm{H}_{2} \mathrm{O}(\mathrm{l})\right)+\Delta_{f} G_{m}^{0}\left(\mathrm{CO}_{2}(\mathrm{aq})\right) \\
& -\frac{1}{6} \Delta_{f} G_{m}^{0}\left(\mathrm{C}_{6} \mathrm{H}_{6}(\mathrm{aq})\right)-5 \Delta_{f} G_{m}^{0}(\bullet \mathrm{OH}(\mathrm{aq})) \\
= & -1185.0308 \mathrm{~kJ} \cdot \mathrm{mol}^{-1}
\end{aligned}
$$

The molar Gibbs energy change of reaction for other organic compounds with $\bullet \mathrm{OH}$ can be calculated by the same method as Reaction (II). The reaction equations for the $\Delta_{r} G_{m}^{0}$ calculation and the calculation results are listed in Table 4 . The corresponding data used are listed in Table 3.

\subsection{Comparisons of the calculation results with the experimental} results

The degradation ability of some typical organic species by AOPs is investigated. All the investigated organic pollutants by 
Table 2

The $\Delta_{f} G_{m, A}^{0}(\mathrm{~g})$ obtained from literatures and the calculated $\Delta_{f} G_{m, A}^{0}(\mathrm{aq})$ at $298.15 \mathrm{~K}$ for 31 organic species.

\begin{tabular}{|c|c|c|c|c|}
\hline \multirow{2}{*}{$\begin{array}{l}\text { System } \\
\text { Chloroethylene }\end{array}$} & \multirow{2}{*}{$\frac{\Delta_{f} G_{m, A}^{0}(\mathrm{~g})[17]\left(\mathrm{kJ} \mathrm{mol}^{-1}\right)}{56.3}$} & \multicolumn{2}{|c|}{ Henry's law constant } & \multirow{2}{*}{$\begin{array}{l}\text { Calculated } \Delta_{f} G_{m, A}^{0}(\mathrm{aq})\left(\mathrm{kJ} \mathrm{mol}^{-1}\right) \\
64.3952\end{array}$} \\
\hline & & 0.038 & [18] & \\
\hline 1,2-Dichloroethane & -73.9 & 0.95 & [19] & -73.7843 \\
\hline Dichloromethane & -68.9 & 0.41 & [20] & -66.7012 \\
\hline 1,1,1-Trichloroethane & -76.2 & 0.068 & [19] & -69.5474 \\
\hline 1,1-Dichloroethylene & 25.4 & 0.039 & [18] & 33.4308 \\
\hline 1,2-Dichloroethylene(cis) & 28.6 & 0.24 & [21] & 32.1263 \\
\hline Trichloroethylene & 19.9 & 0.12 & [19] & 25.1446 \\
\hline Bromodichloromethane & -42.5 & 0.4 & {$[22]$} & -40.2400 \\
\hline Dibromochloromethane & -18.8 & 0.73 & [22] & -18.0313 \\
\hline Trichloromethane & -76.0 & 0.27 & [19] & -72.7656 \\
\hline Tetrachloroethylene & 3 & 0.07 & [19] & 9.5808 \\
\hline Tetrachloromethane & -53.6 & 0.038 & [19] & -45.5048 \\
\hline Dibromomethane & -16.2 & 1.1 & [21] & -16.4478 \\
\hline Tribromomethane & -5 & 1.4 & {$[22]$} & -5.8455 \\
\hline Aniline & -7 & 459.09 & [23] & -22.2056 \\
\hline Ethylbenzene & 131 & 0.12 & [24] & 136.2446 \\
\hline 1,2 -Xylene & 122.1 & 0.25 & [19] & 125.5251 \\
\hline Toluene & 122 & 0.15 & [24] & 126.6915 \\
\hline Styrene & 213.8 & 0.37 & [25] & 216.2533 \\
\hline Benzene & 129.7 & 0.21 & [19] & 133.5574 \\
\hline Chlorobenzene & 89.2 & 0.26 & [20] & 92.5279 \\
\hline Phenol & -32.9 & 2900 & [26] & -52.6749 \\
\hline 1,2-Dichlorobenzene & 82.7 & 0.53 & [27] & 84.2624 \\
\hline 1,4-Dichlorobenzene & 77.2 & 0.42 & [18] & 79.3391 \\
\hline Hexachlorobenzene & 44.4 & 2.1 & [28] & 42.5493 \\
\hline 1,3-Xylene & 118.9 & 0.16 & [19] & 123.4315 \\
\hline 1,4-Xylene & 121.1 & 0.17 & [19] & 125.4812 \\
\hline Formaldehyde & -102.5 & 3100 & [29] & -122.4400 \\
\hline 1,2-Dichloroethylene(trans) & 24.4 & 0.11 & [18] & 29.8603 \\
\hline Pentachlorophenol & -144.1 & 40,000 & [30] & -170.3800 \\
\hline Dimethylamine & 68.5 & 57 & [31] & 58.4660 \\
\hline
\end{tabular}

the photocatalytic experiments and theoretical calculation in this paper could be divided into the following two kinds: chlorinated methane; benzene and its derivatives. As the degradation reaction rate may indicate the degradation order of ease for the organic pollutants, the photocatalytic experiments are performed. All the experiments are carried out in the same conditions (the same reactor and light intensity) and the similar initial concentrations of the organic pollutants. According to our experimental results, the degradation order of ease for the organic pollutants with a longer times' degradation (an hour) is the same as that with the 5 min degradation. So we believe that the degradation reaction rate for the initial 5 minutes may indicate the degradation order of ease very well for the investigated organic systems in this work. And all the photocatalytic degradation reaction of the organic pollutants are performed for $5 \mathrm{~min}$. The degradation reaction rate investigated by the photocatalytic experiments are sequenced from larger to smaller and represented in Table 5. Our calculation results are compared with the experimental results.

\subsubsection{Chlorinated methane}

$\Delta_{r} G_{m}^{0}$ for the degradation reaction of three different chloromethanes with $\bullet \mathrm{OH}$ are calculated respectively. The degradation of organic species is easier and the reactivity is
Table 3

Standard Gibbs energies of formation of species at 298.15 K obtained from literatures.

\begin{tabular}{ll}
\hline System & $\Delta_{f} G_{m}^{0}(\mathrm{aq})\left(\mathrm{kJ} \mathrm{mol}^{-1}\right)$ \\
\hline$\cdot \mathrm{OH}(\mathrm{aq})$ & $13[32]$ \\
$\mathrm{CO}_{2}(\mathrm{aq})$ & $-385.97[33]$ \\
$\mathrm{H}_{2} \mathrm{O}(\mathrm{l})$ & $-237.19[34]$ \\
$\mathrm{Cl}^{-}(\mathrm{aq})$ & $-131.228[35]$ \\
$\mathrm{H}^{+}(\mathrm{aq})$ & $0[35]$ \\
\hline
\end{tabular}

stronger if the calculated $\Delta_{r} G_{m}^{0}$ is smaller. The experimental results by $\mathrm{TiO}_{2}$ photocatalysis from Ollis [7] and the experimental results by the $\mathrm{H}_{2} \mathrm{O}_{2} / \mathrm{UV}$ process introduced in Legrini's review [3] showed the degradation rate of chloromethanes followed the order: $\mathrm{CHCl}_{3}>\mathrm{CH}_{2} \mathrm{Cl}_{2} \gg \mathrm{CCl}_{4}$; and the order of degradation rate by Calza et al. [11] was $\mathrm{CCl}_{4}>\mathrm{CHCl}_{3}>\mathrm{CH}_{2} \mathrm{Cl}_{2}$; While Sabin's work [8] represented $\mathrm{CH}_{2} \mathrm{Cl}_{2}>\mathrm{CHCl}_{3}>\mathrm{CCl}_{4}$. According to our calculation results as is shown in Table 4 , the mineralization ability of chloromethanes follows the order: $\mathrm{CH}_{2} \mathrm{Cl}_{2}>\mathrm{CHCl}_{3}>\mathrm{CCl}_{4}$, and from Table 5, our experimental work shows the degradation order of ease for chloromethanes is $\mathrm{CH}_{2} \mathrm{Cl}_{2}>\mathrm{CHCl}_{3} \gg \mathrm{CCl}_{4}$ according to the degradation rate, which is consistent with our calculation results and verifies the validity of our calculation work. Our calculation and experimental results are in accord with Sabin's experimental work.

Table 4

Mineralization reaction equations and the calculated molar Gibbs energy change of reaction $\Delta_{r} G_{m}^{0}$.

\begin{tabular}{|c|c|c|}
\hline System & Mineralization reaction equation & Calculated $\Delta_{r} G_{m}^{0}\left(\mathrm{~kJ} \mathrm{~mol}^{-1}\right)$ \\
\hline Dichloromethane & $\mathrm{CH}_{2} \mathrm{Cl}_{2}(\mathrm{aq})+4^{\bullet} \mathrm{OH}(\mathrm{aq}) \rightleftharpoons 2 \mathrm{H}_{2} \mathrm{O}(\mathrm{l})+\mathrm{CO}_{2}(\mathrm{aq})+2 \mathrm{H}^{+}(\mathrm{aq})+2 \mathrm{Cl}^{-}(\mathrm{aq})$ & -1108.1048 \\
\hline Trichloromethane & $\mathrm{CHCl}_{3}(\mathrm{aq})+2 \cdot \mathrm{OH}(\mathrm{aq}) \rightleftharpoons \mathrm{CO}_{2}(\mathrm{aq})+3 \mathrm{H}^{+}(\mathrm{aq})+3 \mathrm{Cl}^{-}(\mathrm{aq})$ & -732.8884 \\
\hline Tetrachloromethane & $\mathrm{CCl}_{4}(\mathrm{aq})+2 \mathrm{H}_{2} \mathrm{O}(\mathrm{l}) \rightleftharpoons \mathrm{CO}_{2}(\mathrm{aq})+4 \mathrm{H}^{+}(\mathrm{aq})+4 \mathrm{Cl}^{-}(\mathrm{aq})$ & -390.5472 \\
\hline 1,2-Xylene & $\frac{1}{8} \mathrm{C}_{8} \mathrm{H}_{10}(\mathrm{aq})+\frac{21}{4} \cdot \mathrm{OH}(\mathrm{aq}) \rightleftharpoons \frac{13}{4} \mathrm{H}_{2} \mathrm{O}(\mathrm{l})+\mathrm{CO}_{2}(\mathrm{aq})$ & -1240.7781 \\
\hline Toluene & $\frac{1}{7} \mathrm{C}_{7} \mathrm{H}_{8}(\mathrm{aq})+\frac{36}{7} \cdot \mathrm{OH}(\mathrm{aq}) \rightleftharpoons \frac{22}{7} \mathrm{H}_{2} \mathrm{O}(\mathrm{l})+\mathrm{CO}_{2}(\mathrm{aq})$ & -1216.3156 \\
\hline Chlorobenzene & $\frac{1}{6} \mathrm{C}_{6} \mathrm{H}_{5} \mathrm{Cl}(\mathrm{aq})+\frac{14}{3} \cdot \mathrm{OH}(\mathrm{aq}) \rightleftharpoons \frac{8}{3} \mathrm{H}_{2} \mathrm{O}(\mathrm{l})+\mathrm{CO}_{2}(\mathrm{aq})+\frac{1}{6} \mathrm{H}^{+}(\mathrm{aq})+\frac{1}{6} \mathrm{Cl}^{-}(\mathrm{aq})$ & -1116.4360 \\
\hline Phenol & $\frac{1}{6} \mathrm{C}_{6} \mathrm{H}_{5} \mathrm{OH}(\mathrm{aq})+\frac{14}{3} \bullet \mathrm{OH}(\mathrm{aq}) \rightleftharpoons \frac{17}{6} \mathrm{H}_{2} \mathrm{O}(\mathrm{l})+\mathrm{CO}_{2}(\mathrm{aq})$ & -1109.8958 \\
\hline
\end{tabular}


Table 5

Comparison of representative organic compounds reaction rate by photocatalytic degradation reaction experiments.

\begin{tabular}{llrl}
\hline Organic species & & $C_{0}(\mathrm{ppm})$ & $r_{0}{ }^{\mathrm{a}}\left(\mathrm{ppm} \mathrm{min}^{-1}\right)$ \\
\hline \multirow{3}{*}{ Chlorinated methane } & Dichloromethane & 132 & 2.52 \\
& Trichloromethane & 120 & 2.07 \\
& Tetrachloromethane & 80 & 0.11 \\
& 1,2-Xylene & 100 & 2.56 \\
& Toluene & 90 & 1.57 \\
Benzene and its derivatives & Benzene & 90 & 1.56 \\
& Chlorobenzene & 100 & 1.47 \\
& Phenol & 100 & 1.17 \\
\hline
\end{tabular}

a The average degradation rate in the initial $5 \mathrm{~min}$.

\subsubsection{Benzene and its derivatives}

The calculation results for benzene and its derivatives are sequenced according to $\Delta_{r} G_{m}^{0}$ from smaller to larger and are shown in Table 4. From Table 4, we can see the order of reactivity for benzene and its derivatives is 1,2 -xylene $>$ toluene $>$ benzene $>$ chlorobenzene $>$ phenol, while the order results reported by Legrini et al. [3] is toluene $>$ benzene $>$ phenol > chlorobenzene. The comparison of our calculation results with the experimental results [3] shows some order differences between chlorobenzene and phenol. According to the summary of Glaze and Kang [12] for the rate constants of several organic compounds with hydroxyl radicals from the work of Farhataziz and Ross [13], the degradation rate order is benzene $>$ toluene $>$ chlorobenzene, which represents the different reactivity order of benzene and toluene from the results of [3] and our calculation results. However, according to our experimental validation as is shown in Table 5, the order of reactivity for benzene and its derivatives is consistent with our calculation results, which verifies the reliability of our calculation work. The work here shows that it is reasonable, effective and reliable to evaluate the mineralization reaction abilities for the organic contaminants in AOPs by the calculation of the $\Delta_{r} G_{m}^{0}$.

The work in this paper represents the validity and reliability of our thermodynamic calculations and shows a success of thermodynamics for the application in environmental area. And it shows that the thermodynamics of the degradation reaction for the organic pollutants in AOPs can find the corresponding relationships with the degradation reaction rate. This work shows that the essence of the mineralization reaction ability of the organic pollutants by AOPs is determined by the reaction thermodynamics if the mineralization reaction equations are provided reasonably and written comparably.

Although the limited systems do not bring any generalizations, some trends are obvious. Thermodynamic calculation can also give much useful information for the determination of the mineralization ability of the organic species in AOPs.

\section{Conclusions}

The aim of the present study is to investigate the degradation abilities of various chlorinated aliphatics, benzene and its derivatives in advanced oxidation processes by thermodynamic calculations. We use a simple and effective thermodynamic method to calculate the standard molar Gibbs energy of formation for aqueous organic species. The $\Delta_{r} G_{m}^{0}$ for the organic species with ${ }^{\bullet} \mathrm{OH}$ are calculated to determine the degradation order of ease for the organic species. This work shows that the thermodynamics of the degradation reaction for the organic pollutants in AOPs can find the corresponding relationships with the degradation reaction rate by experimental measurements. The calculated results for the mineralization ability are generally in accordance with the reported and our experimental results, which verifies the validity and reliability of our thermodynamic calculation. This work shows that the essence of the mineralization reaction ability of the organic contaminants by AOPs is determined by the reaction thermodynamics if the mineralization reaction equations are provided reasonably and written comparably. The work in this paper represents a success of thermodynamics for the application in environmental area.

\section{Acknowledgments}

This work was supported by the Chinese National Key Technology R\&D Program (2006AA03Z455), NSFC-RGC (No. 20731160614), the Natural Science Foundation of the Jiangsu Higher Education Institutions of China (08KJB530003), the Chinese National Natural Science Foundation (No. 20706028, No. 20706029, No. B060105, No. 20731160614, No. 20736002) and Program for Changjiang Scholars and Innovative Research Team in University (No. IRT0732).

\section{References}

[1] F.J. Benitez, J. Beltran-Heredia, J.L. Acero, F.J. Rubio, Chemosphere 41 (2000) 1271-1277.

[2] V. Bambang, K. Jae-Duck, J. Environ. Sci. 19 (2007) 513-522.

[3] O. Legrini, E. Oliveros, A.M. Braun, Chem. Rev. 93 (1993) 671-698.

[4] A. Haarstrick, O.M. Kut, E. Heinzle, Environ. Sci. Technol. 30 (1996) 817-824.

[5] J. Dzengel, J. Theurich, D.W. Bahnemann, Environ. Sci. Technol. 33 (1999) 294-300.

[6] M.C. Yeber, K.P. Onate, G. Vidal, Environ. Sci. Technol. 41 (2007) 2510.

[7] D.F. Ollis, Environ. Sci. Technol. 19 (6) (1985) 480-484.

[8] F. Sabin, T. Türk, A. Vogler, J. Photochem. Photobiol. A: Chem. 63 (1992) 99

[9] F.J. Beltrán, J. Rivas, P.M. Álvarez, M.A. Alonso, B. Acedo, Ind. Eng. Chem. Res. 38 (1999) 4189-4199.

[10] D.W. Sundstrom, H.E. Klei, NTIS Publ. nr. PB87-149357 (1986).

[11] P. Calza, C. Minero, E. Pelizzetti, Environ. Sci. Technol. 31 (1997) 2198-2203.

[12] W.H. Glaze, J.W. Kang, Ind. Eng. Chem. Res. 28 (1989) 1573-1580.

[13] Farhataziz, A.B. Ross, Natl. Stand. Ref. Data Ser., Natl. Bur. Stand. (U.S.). U.S. Government Printing Office, Washington, No. 59, 1977.

[14] J.M. Prausnitz, R.N. Lichtenthaler, E.G. de Azevedo, Molecular Thermodynamics of Fluid-phase Equilibria, 3rd ed., Prentice Hall PTR, NJ, 1999.

[15] A. Valtz, A. Chapoy, C. Coquelet, P. Paricaud, D. Richon, Fluid Phase Equilib. 226 (2004) 333-344.

[16] J.P. Amend, H.C. Helgeson, Geochim. Cosmochim. Acta 61 (1) (1997) 11-46.

[17] J.A. Dean, Lange's Handbook of Chemistry, 15th ed., McGraw-Hill, New York, 1999.

[18] J.M. Gossett, Environ. Sci. Technol. 21 (1987) 202-208.

[19] J. Dewulf, D. Drijvers, H. van Langenhove, Atmos. Environ. 29 (1995) 323-331.

[20] J.T. Hoff, D. Mackay, R. Gillham, W.Y. Shiu, Environ. Sci. Technol. 27 (1993) 2174-2180.

[21] D.A. Wright, S.I. Sandler, D. DeVoll., Environ. Sci. Technol. 26 (1992) 1828 1831.

[22] R.M. Moore, C.E. Geen, V.K. Tait, Chemosphere 30 (1995) 1183-1191.

[23] D.S. Jayasinghe, et al., Environ. Sci. Technol. 26 (1992) 2275-2281.

[24] D. Mackay, W.Y. Shiu, R.P. Sutherland, Environ. Sci. Technol. 13 (1979) 333-337.

[25] C.L. Yaws, H.C. Yang, Henry's law constant for compound in water, in: C.L. Yaws (Ed.), Thermodynamic and Physical Property Data, Gulf Publishing Company, Houston, TX, 1992, pp. 181-206.

[26] G.H. Parsons, C.H. Rochester, C.E.C. Wood, J. Chem. Soc. B (1971) 533-536.

[27] D. Mackay, W.Y. Shiu, J. Phys. Chem. Ref. Data 10 (1981) 1175-1199.

[28] T.E.M. TenHulscher, L.E. van der Velde, W.A. Bruggeman, Environ. Toxicol. Chem. 11 (1992) 1595-1603.

[29] X. Zhou, K. Mopper, Environ. Sci. Technol. 24 (1990) 1864-1869.

[30] W.M. eylan, P.H. Howard, Environ. Toxicol. Chem. 10 (1991) 1283-1293.

[31] A.O. Christie, D.J. Crisp, J. Appl. Chem. 17 (1967) 11-14.

[32] G.V. Buxton, C.L. Greenstock, W.P. Helman, A.B. Ross, J. Phys. Chem. Ref. Data 17 (1988) 513-886.

[33] R.A. Alberty, J. Phys. Chem. 99 (1995) 11028-11034.

[34] R.A. Alberty, Arch. Biochem. Biophys. 348 (1) (1997) 116-124.

[35] D.D. Wagman, W.H. Evans, V.B. Parker, R.H. Schumm, I. Halow, S.M. Bailey, K.L. Churney, R.L. Nuttall, J. Phys. Chem. Ref. Data 1 (Suppl. 2) (1982) 1-407. 